\title{
Em torno da mediação: contribuições para fundamentação teórico- epistemológica da categoria nos estudos da informação
}

\section{Reflections on mediation: theoretical-epistemological contributions to information studies}

\author{
Ana Amélia Lage Martins \\ Doutora em Ciência da Informação \\ Instituto Brasileiro de Informação em Ciência e Tecnologia \\ anaamelialagemartins@gmail.com
}

\begin{abstract}
Resumo
O trabalho apresenta e discute a gênese dialética da categoria mediação, destacando as contribuições trazidas pelos trabalhos de Manuel Martin-Serrano e César Bolaño na construção e compreensão dos objetos informacionais.
\end{abstract}

Palavras-chave

Mediação. Mediação e informação. Mediação dialética.

\section{Abstract}

The paper presents and discusses the dialectical genesis of the mediation category, highlighting the contributions made by the works of Manuel Martin-Serrano and César Bolaño in the construction and understanding of informational objects.

Keywords

Mediation. Mediation and information. Dialectical mediation.

\section{INTRODUÇÃO}

O contexto histórico de disseminação do conceito mediação no campo da Comunicação e Informação na América Latina, na década de 1980, tem como marcos históricos fundamentais: a reorganização do capitalismo após uma aguda crise de acumulação; os processos de democratização pelos quais passaram vários países do subcontinente e a emergência de "novos movimentos sociais" que colocavam na cena pública questões (de gênero, ambientais, étnicas, sexuais, etc.) para além das concebidas como propriamente concernentes às relações de trabalho e às classes sociais.

Este momento histórico em que a organização das forças produtivas e as relações de produção se alteravam profundamente foi o pano de fundo para reorientações paradigmáticas nas Ciências Sociais, dentre as quais a Ciência da Informação e a Comunicação.

$\mathrm{Na}$ Ciência da Informação estas reorientações tiveram como base questionamentos sobre os referenciais fisicistas e cognitivos a partir dos quais era compreendida a informação, o que resultou na emergência de perspectivas epistemológicas "alternativas" que passaram a destacar o caráter fundamentalmente social, cultural, histórico e político dos pro- 
cessos informacionais. Na Comunicação latino-americana foi a problematização dos modelos norte-americanos de caráter notadamente funcionalista que pautavam os "estudos de efeitos" dos meios e da indústria cultural que resultou em uma nova abordagem, centrada nas "mediações" (MARTIN-BARBERO, 2009).

É neste momento, quando a Ciência da Informação passa a pensar seu objeto também a partir dos contextos históricos, cultural e socialmente estruturados e estruturantes, onde os sujeitos desempenham papéis ativos e não puramente funções cognitivas na produção, acesso e apropriação da informação; em que a informação é vista como elemento fundamental na construção de projetos democráticos e na participação cidadã, que a categoria mediação se integra de modo definitivo em um "novo quadro conceitual" da Ciência da Informação (ARAÚJO, 2016).

O "advento" ${ }^{1}$ das tecnologias da comunicação (as chamadas $\mathrm{TIC}^{\prime} \mathrm{s}$ ), que passam a penetrar de modo ubíquo todas as esferas da vida porque convertidas em elementos fundamentais da reestruturação capitalista, foi também determinante para a consolidação da mediação e suas variantes (mediações-mediadores) no âmbito dos estudos informacionais. Fazem parte da trajetória que o conceito tem na Ciência da Informação o discurso de surgimento das "novas tecnologias de informação e comunicação", responsáveis por alterar os modos de produção, organização e acesso da informação e modificar o tradicional serviço de referência das bibliotecas, bem como a transformação sistemática das relações operadas pelo Estado, mercado e sociedade civil com a informação, a comunicação e o conhecimento, agora determinantes da exploração do trabalho, da produção de valor e das disputas pelo poder.

Nos últimos anos, a presença marcante da categoria mediação e seus múltiplos sentidos no campo de estudos da informação se converteram em objeto frequente de pesquisa e discussão ${ }^{2}$, sendo hoje crescente o número de trabalhos que têm não apenas utilizado a categoria, como também se dedicado a apreender, neste universo, seus modos de operação, seus significados e suas potencialidades na compreensão de diversos aspectos que envolvem a produção, a distribuição, a organização, o consumo, a apropriação, as práticas e os regimes de informação.

É possível perceber, a partir deste acúmulo, a mediação como uma categoria mobilizada para demarcar, dentre outros: a) toda a ação de interferência realizada por profissionais da informação cujo objetivo é aproximar sujeitos e registros de informação, processo que ao cabo tem por fim a produção de sentidos e a satisfação de "necessidades informacionais" (ALMEIDA JÚNIOR, 2009); b) o caráter processual da construção de significados adjacentes aos procedimentos informacionais - que não se dá de forma imediata, mas apenas por processos onde atuam diversas intervenientes: materiais, técnicas, simbólicas, cognitivas etc. (JEANNERET, 2009); passagem, elo social; c) "ato constitutivo dos processos de construção de sentidos e instância produtora de significação" (PERROTI; PIERUCCINI, 2014, p. 19).

O enfoque na produção de sentidos e significados, na apropriação e interpretação adjacentes aos fenômenos informacionais e que tem como intervenientes os contextos indivi-

\footnotetext{
1 O discurso do "advento das tecnologias" é um marcador importante evidenciado no trabalho de Freitas (2001) na literatura da Ciência da Informação a partir dos anos 1990. Em seu trabalho de doutorado, a autora identifica a tecnologia sendo enfatizada amiúde: a) pela expectativa do porvir, do advento, de uma aproximação incessante; b) pela visão de que esta chegada provoca impactos e transformações em diferentes esferas da vida, o que exige adaptações e rearranjos, c) pela perspectiva de que a penetração tecnológica definidora da Sociedade da Informação - era irreversível ou inevitável.

2 Vide os trabalhos de: Farias, M. G. G. e Farias, G. B (2007), Martins (2010), Silva, F. S., Nunes, J. V. e Cavalcante, L. E (2018) e Malheiros e Silva (2010).
} 
dual e coletivo, material e simbolicamente estruturados, é um marcador importante para pensar a mediação no campo e resulta da influência que teve a teoria da mediação social de Martin-Barbero, na Comunicação e Ciência da Informação da América Latina.

Desde que foi utilizada por este autor, em 1987, como modo de romper com o funcionalismo e o midiacentrismo que marcavam as pesquisas em comunicação e promover um olhar latino-americano que buscava se descolonizar, o uso da categoria mediação-mediações no campo da Comunicação e Ciência da Informação tem sido realizado, em grande medida, para complexificar (em suas dimensões técnicas, semiológicas, políticas, cognitivas etc.) as mais diversas questões que cercam a informação e para destacar a possibilidade múltipla da construção de sentidos e significados decorrente da apropriação social dos meios, o que potencialmente desafiaria o quadro de referências simbólicas das hegemonias, forjando outros modos de produção de identidades, de solidariedade e, especialmente, de ação política.

Sabe-se, contudo, que antes de o polissêmico termo migrar para o campo da Comunicação e da Informação, ele se apresentava como um elemento da Lógica e da Epistemologia na Filosofia Ocidental desde, pelo menos, a Antiguidade Clássica, quando fora utilizado através da perspectiva do "meio-termo" ou "termo-médio" nas Teorias do Conhecimento, na Ética Aristotélica e no Silogismo (ABBAGNANO, 2007).

Seu desenvolvimento como categoria tem como marco histórico fundamental o sistema dialético construído por Hegel, no século XIX, onde figura como "categoria central" (BOTTOMORE, 2010) e, mais tarde, a dialética materialista histórica de Marx.

$\mathrm{Na}$ dialética, tanto idealista quanto materialista, a categoria tem função ontológica, vinculada, de maneira geral, às determinações do ser a partir da negação, da reflexão e do devir (HEGEL, 2017) e à produção do metabolismo entre humanidade e natureza e, portanto, à possibilidade de existência do ser social a partir da mediação do trabalho (MARX, 2011). Opera também com uma função propriamente epistemológica e metodológica, ligada à impossibilidade do conhecimento imediato; às "múltiplas determinações do real" (MARX, 2008), aos nexos estabelecidos entre as partes de uma totalidade complexa; à compreensão dos processos à luz das relações sociais historicamente organizadas em totalidades nas quais se contrapõem elementos implicados entre si. A mediação propõe, do ponto de vista metodológico, um caminho lógico e histórico que revela a essência dos fenômenos que, em sua imediatez, se ocultam por meio de uma aparência, ou por meio de uma forma (MARTINS, 2019, no prelo).

Embora não tenha sido contemplada pela teoria latino-americana das mediações que reivindicou uma "linguagem [...] que mistura saberes e sentires, seduções e resistências que a dialética desconhece" (MARTIN-BARBERO, 2009, p. 262), a perspectiva dialética da mediação pode ser vista na teoria da mediação social, de Martin-Serrano, autor responsável por introduzir dez anos antes de Martin-Barbero, em 1977, o conceito de mediação na Comunicação; e na Economia Política da Informação, da Comunicação e Cultura, que tem nos trabaIhos do brasileiro César Bolãno um expoente do pensamento e da reflexão sobre a mediação dialética no campo da informação e comunicação.

Tendo em vista a inscrição histórica dialética do termo e considerando que todo conceito, especialmente os que migram intensamente de um campo a outro, guarda "significados de origem, sem os quais ele perderia seu poder interpretativo" (MARTELETO, 2007, p. 14), este trabalho busca apresentar perspectivas dialéticas da mediação para a construção e compreensão dos objetos infocomunicacionais, ou seja, dos objetos com os quais se preocupam a Ciência da Informação e a Comunicação, os quais são, diversas vezes, compartilhados por esses dois campos de conhecimento. 


\section{MEDIAÇÃO COMO CATEGORIA DIALÉTICA}

Embora a gênese histórica e filosófica da mediação possa ser rastreada desde, pelo menos, a Antiguidade Clássica a partir do emprego do "meio-termo" ou "termo-médio" na Lógica e na Ética Aristotélica e na Epistemologia, é com a dialética moderna que ela se desenvolve propriamente como categoria (ABBAGNANO, 2007).

Construída por Hegel, no século XIX, a partir de um amplo diálogo crítico com o pensamento filosófico Ocidental, a dialética compreende o sistema das leis do movimento da realidade e, ao mesmo, tempo do pensamento que reflete a realidade.

$\mathrm{Na}$ estruturação deste sistema que Hegel identifica como a própria Ciência, o filósofo alemão integra a contradição como elemento fundamental do raciocínio, o que não era contemplado pela lógica formal.

Ao partir da perspectiva de que tudo que existe está interligado, ou seja, em conexão universal e em constante movimento e transformação, Hegel pensa a contradição como o princípio a partir do qual ser e pensamento existem, como uma condição inerente ao desenvolvimento de todas as coisas, que se processa no âmbito do real e do movimento racional que pensa esse real.

Na dialética hegeliana, totalidade e contradição são, assim, categorias explicativas fundamentais para a apreensão da essencialidade do ser, que coincide com a essencialidade do pensamento.

A contradição implica considerar que a realidade e a análise sobre esse real colocam, fundamentalmente em seu desenvolvimento, a sua contradição, a sua negação: se para a lógica formal o objeto, ou o "ser", era ou não era alguma coisa (A não pode ser "não A"), na dialética ele se formula no encontro com aquilo que não é3: a semente se formula no encontro com o fruto (sua negação e devir), de modo que o seu caráter essencial é o processo de sua transformação em árvore e, subsequentemente, em fruto.

Para Hegel, o ser puro, imediato, é um ser indeterminado, sem conteúdo, sendo primeiramente determinado frente a outro em geral por uma mediação, que provoca a redefinição do ser no interior de si mesmo. A categoria tem, assim, um sentido ontológico ou ontocriativo, vinculado ao princípio da contradição, da negação e do devir, a partir do qual o ser existe.

Considerando o princípio da totalidade, Hegel defende que o conhecimento do Absoluto, da "verdade suprema, concreta e última de todo ser" (HEGEL, 2017, p. 73), que ao mesmo tempo é desenvolvimento de tudo que existe, somente se completa mediante seu desenvolvimento temporal em um processo totalizador, de modo que a essência ou a verdade não podem ser acessadas de modo imediato ao fenômeno, no objeto singular, mas somente tendo em vista suas mediações. A mediação será, então, categoria epistemológica e metodológica vinculada à impossibilidade do conhecimento imediato e aos nexos constitutivos do objeto através dos quais é possível o acesso à sua essência.

Karl Marx continuará, no final do século XIX, a desenvolver a dialética de Hegel invertendo, contudo, seus termos, já que, como é sabido, para ele não é a consciência a responsável por determinar o ser, mas a produção material da vida, do ser social, a determinante na produção da consciência.

\footnotetext{
${ }^{3}$ Este encontro promove uma síntese, superação de um termo por outro ao mesmo tempo que redefinição interna destes termos, que novamente é negada, em um processo dialético totalizador que implica em mudança qualitativa e quantitativa e que, didaticamente, foi traduzido nos termos "tese-antítese-síntese".
} 
Seu interesse é compreender "como os indivíduos produzem a sociedade e a produção de indivíduos socialmente determinados" (MARX, 2008, p. 237), tendo como eixo a produção material da vida, considerada o elemento fundamental para a satisfação das necessidades do corpo, o que só é possível por meio da atividade produtiva do trabalho. A Economia seria, assim, para ele, o modo como a humanidade produz e reproduz coletivamente suas condições de vida.

Assim como em Hegel, a mediação tem caráter ontológico em Marx, o que é notado quando ele pensa o trabalho, a atividade produtiva fundamental para existência do ser social, como mediação entre humanidade e natureza que torna possível a existência humana ${ }^{4}$.

A mediação também será uma categoria epistemológica e metodológica em Marx, quando este pensa o conhecimento como decorrente desta mesma mediação do metabolismo entre humanos e natureza e na necessidade da passagem do real empírico ao concreto (compreendido como a síntese das múltiplas determinações) pela mediação do abstrato.

Na sua Contribuição à Crítica da Economia Política, Marx ressalta que "a produção não é apenas meio para o consumo e o consumo, finalidade para a produção, mas cada qual fornece ao outro o seu objeto: a produção o objeto externo do consumo, o consumo o objeto representado da produção" (MARX, 2011, p.75).

Ele indica com isso que cada um destes polos não apenas é imediatamente o outro, nem tampouco "apenas o medeia, mas cada qual cria o outro à medida que se realiza" (MARX, 2011, p. 75, grifo meu). A criação de consumidores a partir de um modo de consumo é fruto, portanto, de uma mediação da produção, de modo que a produção produz o consumo na medida em que cria o modo determinado, que é também mediação do consumo. Assim, a produção não somente provê de materiais a necessidade como também provê de necessidades os materiais, ou seja, a produção não somente "produz um objeto para o sujeito, mas também um sujeito para o objeto" (MARX, 2011, p. 66).

Em Marx, a categoria vincula-se à criação de uma forma, uma aparência ou "modo de existência" das relações de produção, que se dão a ocultar na existência imediata da mercadoria. É a mediação, metodologicamente, que permite o acesso à essência do modo de produção capitalista, ao mesmo tempo, que possibilita, do ponto de vista histórico, o seu ocultamento, especialmente por uma forma.

Assim, o valor de troca compreenderia uma forma que é modo de existência ou aparência de valor de uso, por sua vez, mediado pela forma-dinheiro (aparência do valor de uso), a mais-valia se media nas formas lucro, juros e renda etc. O dinheiro, por exemplo, como mediação da mercadoria, é o modo de existência (ou aparência) da própria mercadoria, não sendo apenas meio da circulação da produção, mas também sua própria mediação, a sua própria determinação (GUNN, 1987).

Para Marx, o modo objetivo (imediato) com que se apresentam a mercadoria e sua circulação nas sociedades burguesas produz um ocultamento das reais condições de produção de modo que "a forma-mercadoria e a relação de valor dos produtos em que ela se expressa não tem absolutamente nada a ver com sua natureza física e as relações reais que dela resultam" (MARX, 2012, p. 111).

Ele evidencia assim, neste processo, o caráter fetichista do mundo das mercadorias que surge da forma particular de realização do trabalho sob o capitalismo e que produz a forma-mercadoria. Assim, a mercadoria é misteriosa porque encobre os aspectos sociais atinentes ao próprio trabalho, apresentando-os como características materiais e proprieda-

\footnotetext{
${ }^{4}$ Neste sentido Marx também entende os instrumentos de trabalho como mediadores da atividade produtiva.
} 
des sociais inerentes aos produtos de trabalho, ocultando a relação social entre os trabalhos individuais dos produtores e o trabalho total. Deste modo, as relações entre sujeitos assumem uma forma fantasmagórica (fetichista) de relação entre coisas, porque tais relações só assumem o caráter de relações sociais na medida em que são mediadas pelas coisas.

O fetichismo está estreitamente vinculado à noção de aparência, compreendida como forma de manifestação de determinado objeto. Conforme lembra Monfardini (2011), a relação entre essência e aparência dos objetos está no cerne das noções de fetichismo e mistificação.

\begin{abstract}
Apenas para citar um exemplo, a mais-valia se apresenta sob formas mistificadas, como o lucro. E não poderia ser diferente, pois se a mesma se apresentasse tal como é, como trabalho não pago, a sua base de existência não estaria assegurada. Em outras palavras, o lucro é uma das formas necessárias de manifestação da mais valia: não só o lucro (aparência) depende da mais valia (essência) para existir, mas o oposto também é verdadeiro, isto é, a mais valia (essência) dependem para existir de uma forma dissimulada de manifestação (MONFARDINI, 2011, p. 4).
\end{abstract}

Ao pensar em termos de essência e aparência, Monfardini (2011) lembra que uma relação social (essência), por ser mediada por coisas, aparece de imediato como propriedade de coisas, gerando o fenômeno da reificação, de modo que essa relação reificada, tendo um caráter de articulador das trocas, gera também um domínio sobre os indivíduos, caracterizando o fetichismo. Desse modo, para o autor, fica evidente que a sociedade mercantil é marcada por uma aparência que dissimula a sua essência.

Vê-se que a mediação na dialética está eminentemente relacionada com as categorias contradição, historicidade, totalidade, forma-conteúdo, aparência-essência, as quais paulatinamente foram sendo apagadas, especialmente pelas perspectivas que propuseram uma "epistemologia reticular" ${ }^{5}$ em que o conceito eminentemente revolucionário de totalidade foi subsumido em detrimento de uma "lógica das redes".

A perspectiva dialética da mediação ilumina, no entanto, importantes questões do campo informacional e comunicacional, especialmente no cenário contemporâneo de evidente contradição, em que a produção intensa de informação é produção de intensa desinformação, quando a produção da ação contra-hegemônica é também fortalecimento da hegemonia.

Ela pode ser vista pontualmente no campo da Comunicação e Informação em dois momentos: na teoria da mediação social, de Martin-Serrano, e no pensamento dialético de César Bolaño, destacados a seguir.

\title{
3 PERSPECTIVAS DIALÉTICAS DA MEDIAÇÃO NO CAMPO DA INFORMAÇÃO E COMUNICA- ÇÃO
}

\subsection{A mediação social}

La mediación social é um livro escrito por Manuel Martin-Serrano entre maio de 68 e o início da crise capitalista da década de 1970, publicado em 1977, e que apresenta a teoria e metodologia das "mediações sociais", tendo como contexto geral o debate sobre mudanças na natureza, na sociedade e na cultura que marcavam a transformação das sociedades industrializadas em "pós-industriais".

\footnotetext{
${ }^{5} \mathrm{O}$ que pode ser notado nos trabalhos de Bruno Latour e Manuel Castells.
} 
Considerando o acúmulo produzido pelas teorias marxistas, as discussões históricas sobre as relações entre tecnologia e mudança social, a Cibernética, dentre outras referenciais, o autor buscar compreender como, no momento da crise de acumulação da década de 1970 , as contradições que se explicitavam e que culminavam nas movimentações revolucionárias, como as de maio de 68, ao invés de tornarem o sistema capitalista inviável, o reforçavam (MARTIN-SERRANO, 2008).

No prólogo à edição comemorativa de 30 anos de publicação da obra, ele destaca considerar, neste momento, que a análise de como se havia chegado à crise da década de 1970 já estava feita no essencial pelo encontro das teorias críticas que inspiraram a revolução de 68. No entanto, estas não haviam esclarecido o modo pelo qual os sujeitos e grupos foram afetados pelas mudanças e se implicavam com elas.

Assim, neste contexto, o autor destaca que: "a mim me parecia que estavam emergindo novos procedimentos de controle que tornavam possível utilizar as contradições para reproduzir essa ordem contraditória" (MARTIN-SERRANO, 2008, p. 16, tradução minha). A estas operações cujo objetivo era, ao cabo, a instituição de modelos de ordem adequados às necessidades de reprodução do capital ele chamou mediação social.

O conceito de mediação foi entendido pelo espanhol como operações por meio das quais se realizavam os mecanismos renovados de controle que tornavam possível a utilização da contradição na reprodução de um sistema contraditório.

Através de um trabalho histórico e, sobretudo, lógico e semiológico, o autor propôs um referencial teórico-metodológico que buscava explicar as funções desempenhadas pela comunicação e a informação e outras instâncias sociais no contexto de mudança das sociedades capitalistas que trazia formas novas de organização das relações sociais nos níveis econômicos, culturais e políticos.

Para Martin-Serrano (2008), o fato de as contradições evidenciadas na produção hegemônica capitalista não culminarem em conflitos que colocaram em xeque a totalidade do sistema social ${ }^{6}$, indica que estas sociedades possuem sistemas de ajustes muito eficazes, que são os sistemas de regulação institucionalizados, os sistemas de mediação social. Estes sistemas têm em vista produzir, a nível cognitivo, modelos de ajuste para reduzir a dissonância que, a nível real, tem lugar entre a inovação tecnológica, a mudança cultural e a organização social. Eles buscam ordenar a realidade especialmente fragmentando-a, ocultando as suas contradições e centrando a correção dos desajustes sobre os sujeitos, obrigados a adaptarse continuamente às transformações em curso.

A teoria das medições sociais busca destacar, assim, como a contradição reproduz a ordem contraditória e como a alienação produz a identidade (MARTIN-SERRANO, 2008, p. 17).

Martin-Serrano assinala que uma das formas de a contradição reproduzir a ordem contraditória é a instalação de um estado de permanente crise que passa a exigir ajustes macrossociológicos ininterruptos. Ele lembra, a partir de Marx, que embora o sistema de pro-

\footnotetext{
${ }^{6}$ O marco desta revisão histórica são os movimentos de maio de 68 que, orientados para o campo da cultura, defenderam valores que, segundo, Martin-Serrano, não eram apenas progressistas, mas necessários ao novo modelo capitalista no sentido de fazer com que as pessoas se desprendessem dos valores próprios ao Estado de Bem-Estar Social, não mais necessários, e mesmo um entrave, para a nova configuração colocada pelo capitalismo neoliberal. Nancy Fraser faz uma análise próxima, mas mais complexa, ao analisar o modo de incorporação das pautas feministas pelo capitalismo na organização de um "feminismo progressista neoliberal" que acaba alimentando a hegemonia capitalista ao reivindicar, por exemplo, o direito de acesso as mulheres ao campo do trabalho sem questionar, contudo, a totalidade do modelo de produção econômica e reprodução social patriarcal do qual decorrem a exploração e a alienação dos (as) trabalhadores (as).
} 
dução capitalista possa funcionar e se reproduzir em um estado de contradição estrutural, desde o fim da década de 1960 a crise rompeu as barreiras que a mantinha dentro do escopo do mercado, de modo que a existência humana foi sendo "representada em um estado permanente de exceção" (MARTIN-SERRANO, 2008, p. 16).

A partir de então foi instalado discursivamente um estado de crise permanente (e não como uma pausa temporária), de modo que os sujeitos passaram a ser impelidos a se adaptarem e a viverem em um estado contínuo de crise, sem questionar o sistema global. Para lidar com as crises, espera-se, assim, que cada indivíduo "mude" quantas vezes forem necessárias, o que faz com que as contradições sociais sejam gerenciadas como desequilíbrios individuais. Essa forma de controle recorre à mediação social, sendo a da informação, desde a crise de acumulação de 1970, uma das mais eficazes.

O exercício da mediação, como mecanismo de controle e de ocultamento da contradição, opera através de meios imateriais e materiais, que envolvem o desenvolvimento de um setor produtivo, público e privado, dedicado ao ajuste social, ao desenvolvimento de instituições, instâncias, processos e discursos mediadores. "Investimentos em infraestrutura, serviços e bens para a mediação social são, assim, necessários para que o modelo socioeconômico possa durar." (MARTIN-SERRANO, 2007, p. 45, tradução minha).

$O$ autor afirma que as pessoas também investem uma parte de seus recursos em equipamentos que a mediação requer, por exemplo, aparatos audiovisuais e informativos, pagando ou recebendo gratuitamente a ajuda de mediadores especializados quando enfrentam derrotas, anomias ou conflitos. Mas lembra, contudo, que a mediação é utilizada em todas as situações cotidianas e não somente quando há que se manejar uma crise.

O consumo ou a recepção que cumprem funções mediadoras servem aos usuários para informar-se, o que na acepção de Martin-Serrano tem a ver com o conhecimento de como ser, estar e fazer, em consonância (ou em dissonância) com o que há e o que não há, com o que acontece ou não acontece.

É a partir da mediação que a economia capitalista prossegue, assim, com sua inevitável missão de expandir o econômico para todos os territórios e recursos existentes, o que é uma marca definidora da sua forma neoliberal.

Os processos de mitificação e ritualização que recriam o vínculo dos seres humanos com a natureza são identificados também como operações de "mediação cognitiva" e "mediação estrutural" e ambos convergem, segundo Martin-Serrano (2008), nas visões mediadas da realidade que a comunicação produz. Neste caso, os processos de mediação operam com mitos e ritos que se tornaram distintivos da cultura globalizada e primordiais na reprodução da atual ordem socioeconômica. Esta mitologia, segundo ele, ancora-se na concepção de um mundo unificado pelas técnicas e pelo mercado, o que corresponde à utopia burguesa que aparece no Renascimento.

Ao analisar em profundidade, e por meio de um aporte lógico, os modos a partir dos quais opera a televisão, o autor lembra que este foi o primeiro instrumento introduzido nas residências para a recriação icônica do mundo. Desde então, as imagens oferecem a possibilidade de contemplar o que existe, ainda que não se possa ter, e o que acontece, mesmo que não possa ser testemunhado, o que significa que promovem uma comunhão com a "realidade" iconizada ou seja, revestida de atributos sagrados (MARTIN-SERRANO, 2008).

$O$ estudo de Martin-Serrano, que se desdobra em um referencial teórico e metodológico para compreensão dos modelos/esquemas de ajustes a partir das mediações, aproximase de um entendimento dialético da informação ancorado na compreensão dos mecanismos 
de autorganização dos sistemas em que o ruído, ao contrário do que previu a Teoria Matemática da Comunicação, é fonte de produção de ordem ${ }^{7}$.

Assim como é para dialética, a noção de forma, equivalente ao código para MarinSerrano, será fundamental para pensar a produção de representações consensuais e hegemônicas por meio das práticas sociais e comunicativas.

Ao estudar a televisão, Martin-Serrano afirmou que para não colocar em risco a estabilidade dos sistemas normativos e garantir, através das mediações, a reprodução da ordem estabelecida, os mecanismos de controle social via comunicação e informação se centram em neutralizar os possíveis efeitos revolucionários da tecnologia partir de um controle rigoroso do código, dominado pelas grandes empresas da mídia.

Assim, os modelos de ordem da informação e da comunicação se veiculam "principal mente a través de los códigos que organizan los relatos y sólo secundariamente a través de los contenidos que aparecen expresos en esos relatos" (MARTíN-SERRANO, 2008, p. 90).

Isto faz, por exemplo, que a televisão torne compatível a polissemia com a estabilidade de códigos, de modo que a "aparente diversidad de los contenidos expresos del discurso televisivo esconde, a nivel de los códigos, un sistema normativo muy estable" (MARTíNSERRANO, 2008, p. 44), o que pode ser visto ainda hoje nas telenovelas que, embora incorporem conteúdos relacionados à "diversidade" (de gênero, sexual e de raça) mantém intacta a estrutura de representações hegemônicas, assegurando a sedimentação de universalidade às ideologias particulares.

De maneira geral, pode-se dizer que a mediação em Martin-Serrano se constitui em um movimento duplo: político e institucional, psicológico e cognitivo.

Embora não tenha tido amplo reconhecimento no Brasil, seu trabalho apresenta um ponto de inflexão importante aos estudos de comunicação produzidos até então e marcados por um caráter funcionalista, fundamental para o giro epistemológico nos estudos da comunicação da América Latina.

Sua visão possibilitou transformar o estudo das influências dos meios de comunicação demonstrando a existência de formas de controle social que não estão explícitas nas narrativas e que podem ser evidenciadas em metodologias de natureza lógica que tornam possível o reconhecimento destas determinações. Um exemplo são os códigos de construção dos relatos e as formas de organizar a informação que podem ser apreendidos a partir da metodologia dos modelos de mediação social e que tornam possível identificar formas de controle cuja estrutura não pode ser compreendida, segundo ele, por meio de métodos quantitativos ou qualitativos, mas por modelos lógico-semiológicos.

\subsection{A economia política da informação, cultura e comunicação}

A Economia Política da Informação, da Cultura e da Comunicação é uma disciplina relativamente recente que, especialmente a partir das categorias trazidas por Marx, pensa o papel econômico e sociológico que essas atividades assumem na lógica global de produção e reprodução social do sistema capitalista.

No rol das diversas questões contempladas pelo campo estão, dentre outras, a compreensão do funcionamento das indústrias culturais, as especificidades do trabalho no capita-

\footnotetext{
${ }^{7}$ Dantas (2011) lembra que a partir da Teoria Matemática da Informação e da Termodinâmica, o ciberneticista alemão Heinz von Foerster e, posteriormente, o biólogo francês Henri Atlan, formularam o princípio da ordem pelo ruído, através do qual se evidencia como o ruído tem papel crucial na manutenção da neguentropia, ou seja, da capacidade de gerar trabalho por um sistema, especialmente de um sistema vivo.
} 
lismo em sua relação com a informação, comunicação e cultura, o caráter ideológico da mídia, a indústria da cultura como um setor econômico fundamental na organização das estruturas de poder do capitalismo etc.

Em função dos limites e escopo deste trabalho e da amplitude do conhecimento que vem sendo produzido por este campo, a apreensão da categoria mediação, empregada de maneira geral em função do lugar que ocupa no materialismo histórico-dialético, esteve centrada na compreensão do pensamento de Bolaño, no âmbito do qual a mediação tem recebido importante atenção.

César Bolaño, um dos formuladores pioneiros do campo da Economia Política da Informação, Cultura e Comunicação na América Latina, vem destacando a importância epistemológica da categoria mediação para todo o campo da Comunicação, considerando mesmo que ela é definidora desta área de conhecimento, a qual tem como especificidade "estudar as sociedades humanas a partir da mediação" (BOLAÑO, 2012, p. 41).

Partindo do entendimento que a Economia Política crítica aborda, ao cabo, o lugar do capital no processo de constituição do sujeito, no processo de humanização dos sujeitos sociais e de sua emancipação em relação aos poderes da natureza; e tendo em vista a dimensão ontológica da mediação, ele lembra que no âmbito da particularidade histórica do capitalismo, o capital representa uma ruptura ontológica fundamental no processo de construção do sujeito porque permite um desenvolvimento inédito das forças produtivas (BOLAÑO, 2018).

Este fato decorre, segundo o autor, porque a lógica da troca penetra na produção, de modo que os processos de trabalho ficam subordinados aos processos de produção de valor e mais-valor. Dessa forma, suspendem-se os limites físicos e morais para a exploração do trabalho e todo o aparato produtivo opera não mais na perspectiva mercantil simples da equivalência, ou da produção de utilidades para o atendimento de necessidades humanas, mas em uma lógica do valor que se valoriza por meio da apropriação de trabalho não pago (BOLÃNO, 2018).

Isso faz com que o capital se converta em sujeito e que o desenvolvimento das forças produtivas, que potencialmente abriria possibilidades emancipadoras, fique limitado pelas relações de produção alienadas. $O$ autor lembra que essa contradição se apresenta na subordinação dos processos de trabalho, ou seja, processos que teriam como função a produção de valores de uso para satisfação das necessidades, aos processos de valorização do capital.

Com essa inversão, o capital generalizou, pela mediação, a forma-mercadoria, impondo um sistema de "acumulação pela acumulação". Este sistema tem para Bolaño (2018, p. 103) sua máxima expressão na organização do capitalismo financeiro na etapa atual, que subordina a produção do valor e mais-valor à lógica abstrata do capital fictício.

Assim, se o trabalho é responsável por fazer a mediação entre sujeito e suas necessidades, entre humanidade e natureza, no capitalismo essa mediação se apresenta ao (à) trabalhador (a) de forma alienada.

Isto ocorre em função também de uma inversão histórica produzida pelo modo de produção desde a Primeira Revolução Industrial em que as máquinas passam a fazer a mediação entre a necessidade do sujeito (o capital), necessidade de extração de mais-valor, e o objeto de exploração (o trabalhador). É este o momento denominado como subsunção real do trabalho no capital.

A subsunção, conceito desenvolvido por Marx n'O Capital, é categoria fundamental, de acordo com Bolaño (2000, 2018), para compreender esta questão, bem como o caráter no- 
tadamente informacional que tem sido apontado como definidor do capitalismo a partir da década de 1970, no qual cumpre importante função o que o autor denominará de "subsunção do trabalho intelectual".

Em Indústria Cultural, Informação e Capitalismo, o autor afirma que o processo de incorporação gradativa dos recursos da informação e do conhecimento pode ser compreendido por um processo denominado "acumulação primitiva de conhecimento" (BOLAÑO, 2000), base do desenvolvimento tecnológico necessário para que o capital incrementasse sua "capacidade de expandir-se bruscamente e aos saltos" (MARX, p. 517 apud BOLAÑO, 2000, p. $25)^{8}$.

A acumulação primitiva do conhecimento se dá no momento de transição do sistema artesanal medieval para a indústria capitalista no período da manufatura, caracterizando-se como a apropriação, pelo capital, do conhecimento dos (as) artesãos (ãs), o que possibilitou condições objetivas para a revolução permanente das forças produtivas capitalistas e ao mesmo tempo para a destruição dos laços que uniam a velha burguesia comercial e bancária às estruturas de poder do antigo regime.

Decorre desta subsunção a sensível perda de autonomia pelo trabalhador e o controle mantido sobre o processo de produção, "cuja estrutura e ritmo passam a ser ditados pela máquina". A máquina passa, então, a condensar o conhecimento que o capital extraiu do trabalhador artesanal no período da manufatura e a desenvolver outras máquinas, com o apoio das ciências. Assim, é que ela, máquina, passa a usar o trabalhador - e não mais o contrário - e o capitalismo pode expandir-se, revolucionando o modo de produção (BOLAÑO, 2007).

Cumpre lembrar que a expansão capitalista a níveis globais e a consolidação de um sistema financeiro articulado exigiram, como se sabe, o desenvolvimento e expansão dos sistemas de comunicação e transporte, o que fez com que a constituição do chamado "capitalismo monopolista" fosse acompanhado por necessárias transformações técnicas nestes campos, contribuindo para confirmar e potencializar as tendências de articulação social da informação à lógica do desenvolvimento capitalista.

De acordo com Bolaño (2007, p. 37), a separação entre trabalho manual e intelectual, que "está na origem da ruptura do poder das corporações de oficio" e sua reunificação no interior do capital acabará gerando a constituição de uma camada particular de trabalhadores intelectuais, relativamente autônomos, sobretudo no interior da grande empresa e do Estado no período do capitalismo monopolista. Ele aponta que o significado do desenvolvimento das tecnologias da informação e da comunicação vinculadas à chamada "Terceira Revolução Industrial ${ }^{9 "}$ reside justamente na subsunção desse trabalho intelectual, o que vem acompanhado de uma intelectualização geral de todos os processos de trabalho convencionais e do consumo, de modo que o conjunto das relações de produção e das relações sociais em geral se altera para adequar-se às novas exigências da acumulação capitalista.

A compreensão destes processos que desaguaram no modo específico de produção capitalista gestado desde a crise de 1970 e que tem sido caracterizado como "informacional"

\footnotetext{
${ }^{8}$ Para Marx, como o capital, por sua natureza, tende a superar barreiras espaciais, a criação de condições físicas de intercâmbio (como os meios de comunicação e de transporte) se converte na necessidade de anulação do espaço pelo tempo, de modo que o conjunto "meios de comunicação e transporte" deve ser visto como integrante das condições gerais para a reprodução do capital, tendo função na constituição dos mercados de consumo e no fornecimento de matérias primas e produtos intermediários (BOLAÑO, 2000).

${ }^{9} \mathrm{O}$ autor lembra que o elemento principal da Primeira Revolução Industrial foi a máquina-ferramenta, o da Segunda, a produção de máquinas por meio de máquinas e o da terceira o desenvolvimento da microeletrônica ou das "tecnologias da inteligência".
} 
deve ser entendido, de acordo com o autor, considerando o caráter de mediação que tem o trabalho, as especificidades do trabalho cultural e do trabalho intelectual em geral.

A mediação realizada pela Indústria Cultural (os meios) também é vista sob o conceito marxiano de subsunção (das mediações), explicitando a centralidade do trabalho cultural.

A importância do fator tecnológico é destacada na subsunção real porque, segundo Bolaño (2018), permite uma progressão da subsunção do trabalho e, por conseguinte, a expansão da lógica capitalista e da exploração do trabalho vivo.

Assim, o autor lembra que:

\begin{abstract}
As grandes estruturas de mediação social que são os meios de comunicação de massa e as indústrias culturais só podem funcionar como tal porque subsumem trabalho de uma classe particular (trabalho cultural, criativo, de mediação). Sem isso, toda a estrutura da velha Indústria Cultural, como toda a estrutura das novas redes telemáticas, não passaria de um montão de cabos, equipamentos e edifícios inertes, que apodreceriam pela ação do tempo (BOLAÑO, 2018, p. 105)
\end{abstract}

A Indústria Cultural, entendida como estrutura de mediação entre as necessidades de acumulação e a reprodução simbólica do mundo vivido, é vista também pela perspectiva de manifestação das contradições da informação no que se refere à comunicação de massa existente sob o capitalismo monopolista. A informação, assim, se constitui em aparência que mascara a essência do modo de produção.

Isto pode ser evidenciado, segundo ele, desde a construção do ideal burguês de liberdade de informação, necessária à aparência de liberdade, igualdade e propriedade relativos ao universo da troca.

De maneira geral, a mediação é entendida pelo autor a partir da perspectiva da subsunção que se interpõe entre os sujeitos e a sua realização ou satisfação de suas necessidades a partir do trabalho sob o capitalismo e o papel das tecnologias decorrentes da aliança entre ciência e capital.

Para ele, analisar o tema da emancipação hoje no campo da comunicação e informação implica definir, num primeiro momento, a mediação por subsunção do trabalho cultural para somente, num segundo, buscar saber se "outra mediação é possível" (BOLAÑO, 2018).

Neste debate, o autor coloca a relevante questão de que:

O surgimento de novas formas de mediação social e de novos padrões de organização dos movimentos sociais demonstra a existência de toda uma nova cultura capitalista, ligada à lógica do capital fictício e suas contradições. Nesse processo, é de fundamental importância a expansão das tecnologias da informação e da comunicação e da organização dos processos de trabalho intelectual através de redes telemáticas, que vão além da, já muito avançada, automação flexível, graças a um movimento de digitalização geral do mundo, decorrência da revolução microeletrônica, que garante uma extensa subsunção do trabalho intelectual e de intelectualização geral de todos os processos produtivos e do consumo (BOLAÑO, 2012, p. 20).

\title{
4 CONCLUSÕES
}

O emprego da categoria mediação-mediações pôde ser visto na Comunicação e Ciência da Informação como uma chave de leitura que permitiu perceber, especialmente a partir de Martin-Barbero, a potencialidade contra-hegemônica e emancipadora que as práticas infor- 
macionais, comunicacionais, especialmente organizadas a partir dos dispositivos tecnológicos, traziam para o pensamento teórico e para a consecução dos objetivos de diversos movimentos sociais, para o surgimento de novos espaços e linguagens políticas, para maior descentralização do poder no campo social e para o fortalecimento das lutas que culminariam em uma grande transformação das sociedades latino-americanas.

A possibilidade ampla e aberta da construção de sentidos e significados decorrente da apropriação social das tecnologias que têm em vista a transgressão e o desafio ao quadro de referências simbólicas hegemônicas, a produção de modos plurais de produção de identidades, de solidariedade e, especialmente, de ação política, se apresentam, assim, elementos importantes e significativos destes olhares.

O momento histórico de análise das mediações por parte de Martin-Barbero é, no entanto, o mesmo em que a forma-informação, especialmente a partir da disseminação dos meios, passa a cumprir novo papel estratégico na reestruturação capitalista forçada pelo ciclo de crises de acumulação vivido nos anos de 1970, e que culminaria, conforme aponta Bolaño (2000), na subsunção do trabalho intelectual, na intelectualização dos processos de trabalho e consumo, cuja expressão máxima pode ser vista no fenômeno atual da "uberização". O que mirava essa "virada informacional" do capitalismo era a superação dos entraves que a rigidez fordista impunha, o estabelecimento de novos meios e mecanismos de absorção do capital sobreacumulado e, especialmente, sua expansão para territórios ainda não totalmente colonizados, como os afetos (LOPES, 2006).

Assim, os avanços em termos de desenvolvimento de infraestrutura informacional bem como a possibilidade expandida de produção de conteúdos e significados diversos trazidos pelo uso social dos meios e que foram amplamente defendidos no Brasil por iniciativas como o Programa Sociedade da Informação, não apenas significava a potência emancipadora e de desenvolvimento que tinham a informação e a comunicação no âmbito de um projeto de nação, mas, fundamentalmente, que estas seriam essenciais para que o novo modo de produção - neoliberal e rentista - colocado para os países em desenvolvimento seguisse seu rumo.

A forma-informação, neste sentido, se converte na própria mediação necessária para o estabelecimento de novas forças produtivas e mecanismos de gerenciamento, novas formas de subsunção do trabalho ao capital, de articulação entre produção e consumo e, especialmente, para alterações no modo de vida (LOPES, 2006). Por meio de discursos fetichizados que "colaram" ao conceito de informação os ideais de descentralização, ampliação de vozes, transparência, controle social e democratização, a informação se transformou, como mediação, em pura aparência, o que pode ser visto em fenômenos ulteriores, como nas tão propagadas "fake news".

Considerando que o capitalismo generaliza e repõe, continuamente, em todas as camadas da existência social e a partir de diversos mecanismos, processos e estruturas, formas de pensar e agir determinadas pelas exigências da reprodução do capital, o objeto informacional da contemporaneidade pode ser apreendido, pela dialética, na esfera mediacional da recriação contínua das fronteiras do sistema para sua expansão, bem como de utilização da contradição para a reprodução de um sistema marcadamente contraditório.

Assim,

analisar a centralidade que a informação, o conhecimento e as TICS assumiram na atual lógica reprodutiva do capital, bem como as contradições e resistências que esta centralidade libera, exige um aporte teórico que [...] pense o papel produtivo das comunicações, da informação e da cultura como eficazes instâncias de media- 
ção entre as necessidades de acumulação do capital e a reprodução simbólica do mundo vivido (LOPES, 2006, p. 17, grifo meu)

O olhar dialético para as mediações a partir das noções de forma e aparência na apreensão das práticas que envolvem os dispositivos de informação e comunicação, ressalta, assim, a relevância de se pensar a dimensão fetichista que atravessa a produção e o uso das tecnologias de informação e comunicação, iluminando o processo social ocultado pela compreensão das técnicas como algo coerentes em si, como simples decorrências do progresso científico ou como resposta às necessidades sociais (MARTINS, 2019, no prelo).

A mediação permite, desta maneira, perceber pelas articulações do real lógico e do real histórico, a interconexão necessária e contraditória dos fenômenos relativos à dinâmica processual do objeto informacional, especialmente em sua manifestação singular. Neste sentido, uma prática informacional cuja aparência é contra-hegemônica também pode ser vista, pela dialética forma-conteúdo também como essencialmente hegemônico.

Um exemplo disto seriam as práticas informacionais que se multiplicam na Internet a partir do "ativismo digital". Se as ações políticas contestadoras que têm como lógica organizativa os fluxos da informação nas redes telemática digitais podem ser percebidas como mobilizadoras de conteúdo contra-hegemônico, sua veiculação através de formas ou códigos estruturados, organizados e distribuídos pelas grandes corporações capitalistas transnacionais da infotelecomunicação, opera sob os limites de uma imensa força hegemônica do capital, representante ela própria, muitas vezes, pelos graves problemas e questões contra os quais, pela informação e comunicação, se luta. Neste sentido, a análise de uma prática informacional pelas mediações não pode se exaurir nos sentidos e significados produzidos, compartilhados e disseminados, mas na necessária relação dialética entre o sentido mobilizado a partir dos processos e dispositivos informacionais, e as dinâmicas contraditórias da produção econômica e da reprodução social. No cenário de grande contradição e explosão informacional, a mediação permite entrever, mesma na produção de conteúdos contrahegemônicos, a hegemonia sendo produzida pela forma, a qual os diversos atores em disputa incorporam e mobilizam em suas lutas cotidianas.

Assim, se a TV foi fundamental para produzir, não sem resistências, modos de vida ou subjetividades adequadas aos valores necessários para reprodução do capitalismo monopolista, como apontam Bolaño (2000) e Martin-Serrano (2008), a produção das formas microdocumentárias (JEANNERET, 2015), como memes, que disseminam e consolidam verdadeiros cenários de práticas, também podem ser compreendidas no âmbito da grande estrutura mediacional que se converteu a Internet ao subsumir a velha indústria cultural do século XX (BOLAÑO, 2018). Sua principal função (mediação), além de produzir valor a partir das informações que os usuários fornecem com suas práticas e que são objeto importante da produção do consumo individualizado é articular - não sem resistências - uma racionalidade e subjetividade adequadas ao momento neoliberal. É este regime de produção de subjetividade que faz, dentre outros, com que as opiniões e os rastros de uso produzidos pelos internautas possam ser vistos não propriamente como elementos atinentes aos debates travados na web, mas como modos de expressão de si mesmo, como elementos que se organizam por uma lógica da visibilidade e do prestígio.

A categoria mediação cumpre revelar, neste sentido, no campo da Ciência da Informação, aquilo que se oculta (dialeticamente revelando-se) nos fenômenos informacionais, evidenciando, assim, a complexa dialética entre a informação, o econômico e o social, a dominação e resistência, a manipulação e práxis contra-hegemônica na qual se inscrevem todas as práticas de produzir, acessar e fazer circular informação. 


\section{REFERÊNCIAS}

ALMEIDA JÚNIOR, O. F. Mediação da informação e múltiplas linguagens. Tendências da Pesquisa Brasileira em Ciência da Informação, João Pessoa, v. 2, n. 1, p.89-103, jan./dez. 2009. Disponível em: http://www.brapci.inf.br/index.php/article/download/7871. Acesso em: 11 set. 2018.

ARAÚJO, C. A. A. Novo quadro conceitual para a Ciência da Informação: informação, mediações e cultura. Tendências da Pesquisa Brasileira em Ciência da Informação, João Pessoa, v. 9, n. 2, p. 1-17 set./dez. 2016.

BOLAÑO, C. R. S. Indústria cultural, informação e capitalismo. São Paulo: Hucitec/Polis, 2000.

BOLAÑO, C. R. S. Trabalho, comunicação e desenvolvimento. Liinc em Revista, v.3, n. 1, 2007. Disponível em: http://revista.ibict.br/liinc/article/view/3115/2806. Acesso em: 12 ago. 2018.

BOLAÑO, C. R. S. Campo aberto: para a crítica da epistemologia da comunicação. Sergipe: Fapitec, 2012.

BOLAÑO, C. R. S. Crítica e emancipação nos estudos da informação, da comunicação e da cultura. Epitic, Rio de Janeiro, v. 20, n. 1, p. 100-110, 2018.

BOTTOMORE, T. Dicionário do pensamento marxista. São Paulo: Zahar, 2010.

DANTAS, M. Trabalho com informação: valor, acumulação, apropriação nas redes do capital. Rio de Janeiro: CCFCH-UFRJ, 2012.

FARIAS, M. G. G.; FARIAS, G. B. Mediação na Ciência da Informação: uma análise bibliométrica na coleção Benancib, RICl - Revista Ibero-Americana de Ciência da Informação, n. 10, v. 2, p. 332-349, 2017. Disponível em:

http://periodicos.unb.br/ojs248/index.php/RICl/article/view/25215/18635. Acesso em: 11 set. 2018.

FREITAS, L. S. Na teia dos sentidos: análise do discurso da Ciência da Informação sobre a atual condição da informação. 2001. 245f. Tese (Doutorado em Ciências da Comunicação), Escola de Comunicações e Artes, Universidade de São Paulo, São Paulo. 2001.

GUNN, R. Marxism and mediation. Common Sense, n. 2, jul. 1987.

HEGEL, W. F. Ciência da Lógica. Vozes. Petrópolis, 2017.

JEANNERET, Y. A relação entre uso e mediação no campo de pesquisa em informação e comunicação na França. RECIIS, Revista Eletrônica de Comunicação, Informação e Inovação em Saúde, v. 3, n. 3, p. 25-34, set. 2009. Disponível em: https://www.reciis.icict.fiocruz.br/index.php/reciis/article/view/753/1395. Acesso em: 12 
ago. 2018.

JEANNERET, Y. Analisar as "redes sociais» como dispositivos infocomunicacionais: uma problemática. In : TOMAEL M. I.; MARTELETO, R. M. (orgs.) Informação e Redes Sociais: interface de teorias, métodos e objetos. Londrina: Eduel, 2015, p. 11-31.

LOPES, R. S. Informação, conhecimento e valor. 2006. 174 f. Tese (Doutorado em Filosofia) Faculdade de Ciências Humanas e Filosofia, Universidade de São Paulo, 2006, 207p.

MARTINS, A. A. L. Mediação: categoria ontológica, lógica, epistemológica e metodológica. Investigaciones Biblitecológicas, 2019 (no prelo)

MARTINS, A. A.L.. Mediação: reflexões no campo da Ciência da Informação. 2010. 252 f. Dissertação (Mestrado em Ciência da Informação), Escola de Ciência da Informação, Universidade Federal de Minas Gerais, Belo Horizonte.

MARTIN-BARBERO, J. Dos meios às mediações: comunicação, cultura e hegemonia. Rio de Janeiro: UFRJ, 1997.

MARX, K. Grundrisse. São Paulo: Boitempo, 2011.

MARX, K. Contribuição à crítica da economia política. São Paulo: Expressão Popular, 2008.

MARX, K. O caráter fetichista da mercadoria e seu segredo. In: JENKINGS, I.; SADER, E. (org). As armas da crítica: antologia do pensamento de esquerda. São Paulo: Boitempo, 2015. p 110-121.

MARTIN-SERRANO, M. La mediación social: Edición conmemorativa del 30 aniversario, Madrid: Akal, 2008

MONFARDINI, R. D. Sobre o fetichismo da mercadoria como base da mistificação da origem da riqueza. In: ENCONTRO DA ASSOCIAÇÃO NACIONAL DE ECONOMIA, 39, Foz do Iguaçu. Anais... Foz do Iguaçu: ANPEC, 2011.

PERROTTI E., PIERUCCINI, I. A mediação cultural como categoria autônoma. Informação \& Informação, Londrina, v. 19, n. 2, p. 1-22, 2014. Disponível em:

http://www.uel.br/revistas/uel/index.php/informacao/article/view/19992/17341. Acesso em: 12 ago. 2018.

SILVA, A. M. Mediação e mediadores em Ciência da Informação, Prisma.com, n. 9, p. 1-37, 2010. Disponível em: https://repositorio-aberto.up.pt/bitstream/10216/26174/2/000106387.pdf. Acesso em: 12 ago. 2018.

SILVA, F. S.; NUNES, J. V. CAVALCANTE, L. E. O conceito de mediação na Ciência da Informação brasileira: uma análise a partir da BRAPCI; Brazilian Journal Of Information Science, n. 2, v. 2, p. 33-43, 2018. 